\title{
A COMPARATIVE ANALYSIS OF DROUGHT INDICES ON VEGETATION THROUGH REMOTE SENSING FOR LATUR REGION OF INDIA
}

\author{
Richa Dhawale $^{1 *}$, Saikat K. Paul ${ }^{1}$ \\ ${ }^{1}$ Department of Architecture and Regional Planning, Indian Institute of Technology Kharagpur, India - \\ (dhawalericha, s9paul)@gmail.com
}

Commission V, SS: Disaster Monitoring, Damage Assessment and Risk Reduction

KEYWORDS: Agriculture drought, Vegetation Condition Index (VCI), Temperature Condition Index (TCI), and Vegetation Health Index (VHI), drought assessment.

\begin{abstract}
:
Drought intensifies stress on the water resource which is already in a critical condition due to rapid urbanization and population growth thus, affecting people, economy, and environment. The drought conditions are worsening in many parts of India due to deficit rainfall, change in land and surface temperature, and vegetation pattern coupled with mismanagement of water resources and poor governance. The present study conducted for Latur, Marathwada is an agricultural rich land which is severely affected due to prolonged drought conditions. A comparative study is presented using the three drought indices VCI, VHI, TCI to analyze the vegetation condition for drought years. The results through TCI detects the drought only during the dry period or in the months where the temperature is high. The VCI detects drought conditions as more sensitive in wet seasons. The VHI combines both the indicators to give comprehensive results about drought conditions. Further, Land Surface Temperature study is conducted to substantiate the analyzed drought conditions. Our study illustrates that the comparative analysis of various indices represents a better interpretation and monitoring of drought for the areas which are majorly affected due to vegetative drought.
\end{abstract}

\section{INTRODUCTION}

Drought is one of the most complex phenomena where the region faces several failure conditions of economic loss. Wilhite \& Glantz (1985) have categorized different types of drought as meteorological drought, hydrological drought, and agricultural drought. Based on this categorization, various researchers have developed different indicators to analyze the severity and intensity of drought conditions. Meteorological drought defines the dryness of an area. Hydrological drought occurs when the low water supply is evident in streams, rivers or groundwater and it usually succeeds Meteorological drought. Whereas, Agriculture drought refers to the lack of moisture in the soil causing a decline in crop growth and production. The loss in crop production in turn affects the agricultural economy.

The agricultural sector contributes the major share of GDP and is considered to be the pillar of India's economy. Currently, India's $18 \%$ of GDP depends on agriculture sector which was highest during the time of Indian Independence but has declined in due course as seen in figure 1 . As observed over the last few decades,

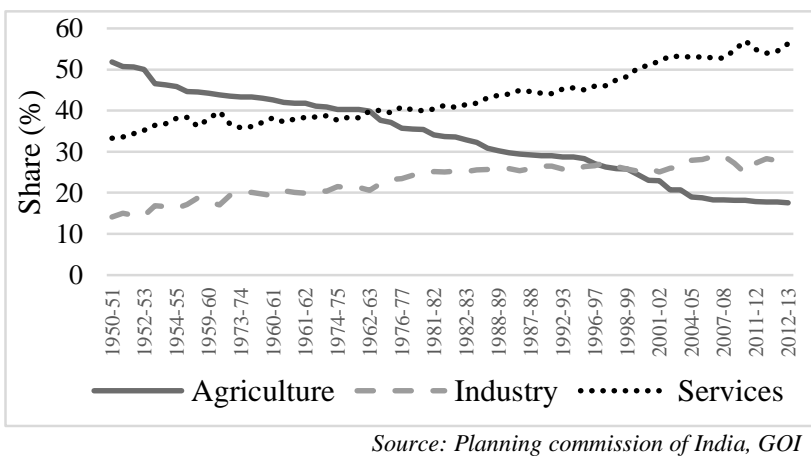

Figure 1: GDP rate for India the agricultural losses are increasing due to uneven precipitation levels and climate change.

In the recent past, satellite-based monitoring is widely used to detect changes from global to national scale including drought (Ghaleb, Mario, \& Sandra, 2015). It helps in analyzing the spatial and temporal changes over the years for larger geographical regions. Drought monitoring is extensively studied using different satellite sensors like AVHRR and MODIS. The present study is associated with analyzing the agricultural conditions in drought-prone regions through Landsat data using vegetation indices. The study analyses the soil moisture condition, thermal stress and vegetation health using VCI, TCI and VHI respectively. These indices are retrieved from the Normalised Difference Vegetation Index (NDVI) and Land Surface Temperature (LST) or Brightness Temperature (BT) (Bhuiyan, 2004), which are both derived through Landsat data. The study undertakes a comparative analysis of these indices to formulate a framework for assessing agricultural drought. Wilhite (2005) has also provided a complete study of analyzing drought using different suitable indices.

\section{STUDY AREA - LATUR REGION}

The present study is conducted for Latur District located in Marathwada. It lies to the South-East of Maharashtra on the border of Maharashtra and Karnataka. As per 2011 census, it has an average population of 2,455,543 with an area of 7,157 square kilometers (District Census, 2011). The population growth rate over the decade 2001-2011 is estimated to be $18.04 \%$. The geographical location of Latur is illustrated in figure 2. It is situated at an average elevation of 631 meters above mean sea level. The regions have a tropical climate which receives acute precipitation levels with an average of $600 \mathrm{~mm}$ and an average temperature of $24^{\circ} \mathrm{C}$ to $39.6^{\circ} \mathrm{C}$. It witnesses prolonged drought

\footnotetext{
${ }^{*}$ Corresponding author
} 
conditions affecting the vegetation cover of the region. The region confronts cracking in soil during summer seasons due to its chemical composition.

Sai weir, Sai Barrage and Dhanegaon Dam on the Manjra river are the three major water sources in Latur. Other available water resources are located at more than $50 \mathrm{~km}$ distance. The annual average rainfall received for the region is almost negligible for the months November till March which indicates the amount of rainfall received during winters is less compared to summers. There is an excessive use of borewells by households to meet the unmet water demand. This has increased the number of borewells to 90,000 leading to a shortage of water for crops and other vegetation further deteriorating groundwater levels (CDP, 2010). This has happened due to zero success rate achievement even after drilling up to $60 \mathrm{~m}$ for borewell in the region.

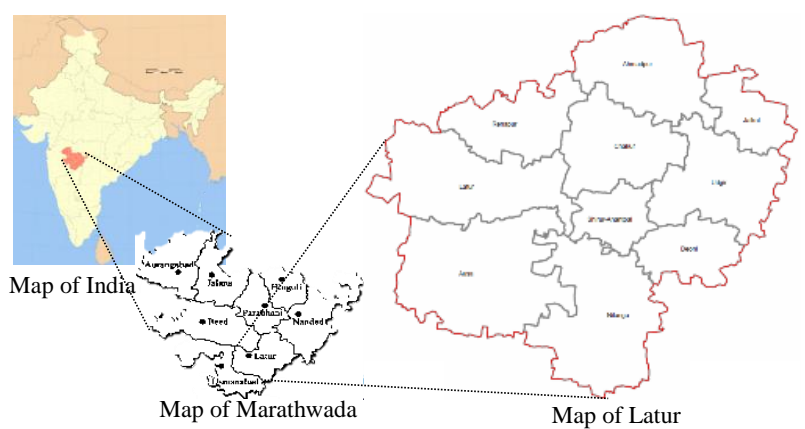

Figure 2: Geographical location of Latur

The present study for the Latur district analyses the agricultural drought. Latur is primarily dependent on the agricultural economy chiefly sugarcane production. Sugarcane shares the maximum percent of the total cultivated land for Latur. It is a water-intensive crop, further increasing the severity of drought. The drought in the year 2014 and 2015 had hit the farmers hard with agricultural yield falling by $20 \%$. In the next year 2016, the worst drought hit the region after 1972 which reduced the farm production by $40 \%$ to $50 \%$, manifesting in a higher farmer suicide rate. As the district's economy is majorly dependent on the agricultural sector, it gets highly affected due to drought conditions. Hence, a system which analyses and monitors the impacts of drought on the agricultural sector is essential for this region.

\section{METHODOLOGY}

Past studies which are associated with drought assessment have described parameters to reduce effects of drought. However, the need is to have a region-specific approach analyzing all the types of droughts affecting different sectors of a region. The present study delineate the impact of drought on agricultural sector using drought indices. The spatiotemporal patterns of seasonal drought indicated through these indices have been discussed. Furthermore, comparison of these indices is undertaken to understand the most effective drought index for analyzing the agricultural drought conditions. The Landsat data required for the analysis was taken from USGS ${ }^{2}$.

Drought is a phenomenon which is difficult to estimate, interpret and address solely using one indicator, unlike other natural hazards which have a definite start and end of occurrence. Our study aims to perform a comparative analysis using three indices, namely Vegetation Condition Index (VCI), Temperature

\footnotetext{
${ }^{2}$ United States Geological Survey

${ }^{3}$ World Meteorological Organization
}

Condition Index (TCI), and Vegetation Health Index (VHI), which are selected by its application of use as well as data availability. We selected the indices from a list given in Handbook of drought indices by $\mathrm{WMO}^{3}$ and $\mathrm{GWP}^{4}$ (Svoboda \& Fuchs, 2017).

\subsection{Vegetation Cover Index (VCI): Moisture stress}

Vegetation Cover Index is used to analyze a region using Landsat data focusing on the impacts of drought on vegetation. It analyses the duration and severity of drought by noting vegetation changes and comparing them with historical values (Svoboda \& Fuchs, 2017). It is an NDVI based index which analyses the NDVI values of historical data to assess the soil moisture condition of a region. The VCI values are further reclassified from 0 to 100 to analyze the severity of drought conditions (Kogan, 2003). The equation for $\mathrm{VCI}$ is given by:

$$
V C I_{i}=\left(\frac{N D V I_{i-} N D V I_{\min }}{N D V I_{\max }-N D V I_{\min }}\right) \times 100
$$

where

$\mathrm{NDVI}_{\mathrm{i}}=$ seasonal average smoothed weekly NDVI $\mathrm{NDVI}_{\min } \& \mathrm{NDVI}_{\max }=$ multilayer absolute minimum and maximum respectively;

\subsection{Temperature Condition Index (TCI): Thermal stress}

Drought multiplies when high temperature is coupled with poor soil moisture condition. Hence, the vegetation health due to thermal effect can be effectively traced using TCI (Kogan, 2002). It analyses the historical records of Land Surface Temperature (LST) retrieved from Brightness Temperature (BT) of a specific period and month. Further, it compares the minimum and maximum values of LST to determine spatial vegetation drought (Kogan, 2001; Sivakumar et al., 2011). The equation for calculating LST is given as:

$$
T C I_{i}=\left(\frac{L S T_{\max }-L S T_{i}}{L S T_{\max }-L S T_{\min }}\right) \times 100
$$

where $\quad \mathrm{LST}_{\mathrm{i}}=\mathrm{LST}$ value for current month

$\mathrm{LST}_{\min } \& \mathrm{LST}_{\max }=$ multilayer minimum and maximum temperature respectively;

\subsection{Vegetation Health Index (VHI):}

It combines VCI and TCI correlating the thermal stress and soil moisture to give total vegetation health condition. It is stronger with vegetation cover than an individual index. It demonstrates better suitability in detecting vegetation condition affected due to drought as it considers both VCI and TCI in the calculations. The equation for $\mathrm{VHI}$ is given by:

$$
V H I_{i}=0.5 V C I_{i} \times 0.5 T C I_{i}
$$

where $\quad \mathrm{VCI}_{\mathrm{i}}=$ seasonal average Vegetation Cover

$\mathrm{TCI}_{\mathrm{i}}=$ seasonal average Thermal stress

\section{RESULTS AND DISCUSSION}

The spatial and temporal variations in vegetation cover is studied for Latur region. Agricultural droughts have been assessed through three indices described in handbook of drought indices. India faced the most drought hit periods during the years 1918 ,

\footnotetext{
${ }^{4}$ Global Water Partnership
} 
1972, 1987, 2002, 2000, 2009 and 2015. Therefore, drought risk map has been produced using Landsat data for the year 2015, 2009 , 2000. Later, we compared these vegetation indices for 2009 and 2000 for the month of April and December to analyze the effects of drought on vegetation over the years. Our primary objective is to spatially visualize the results obtained from the analysis of the three indices. All three indices use remotely sensed data defining different drought conditions.

\begin{tabular}{|c|c|}
\hline Drought & Values \\
\hline Extreme Drought & $<10$ \\
\hline Severe Drought & $<20$ \\
\hline Moderate Drought & $<30$ \\
\hline Mild Drought & $<40$ \\
\hline No Drought & $\geq 40$ \\
\hline
\end{tabular}

Table 1: classification of VCI, VHI, TCI values for drought

Through the VCI and TCI maps, the most affected areas due to drought were traced. The first index shows that majority of the northern part of Latur district is affected by extreme to severe drought. Whereas, the latter shows the mild to no drought conditions for the same region. In addition, Latur City to the west is also showing extreme to severe drought conditions.

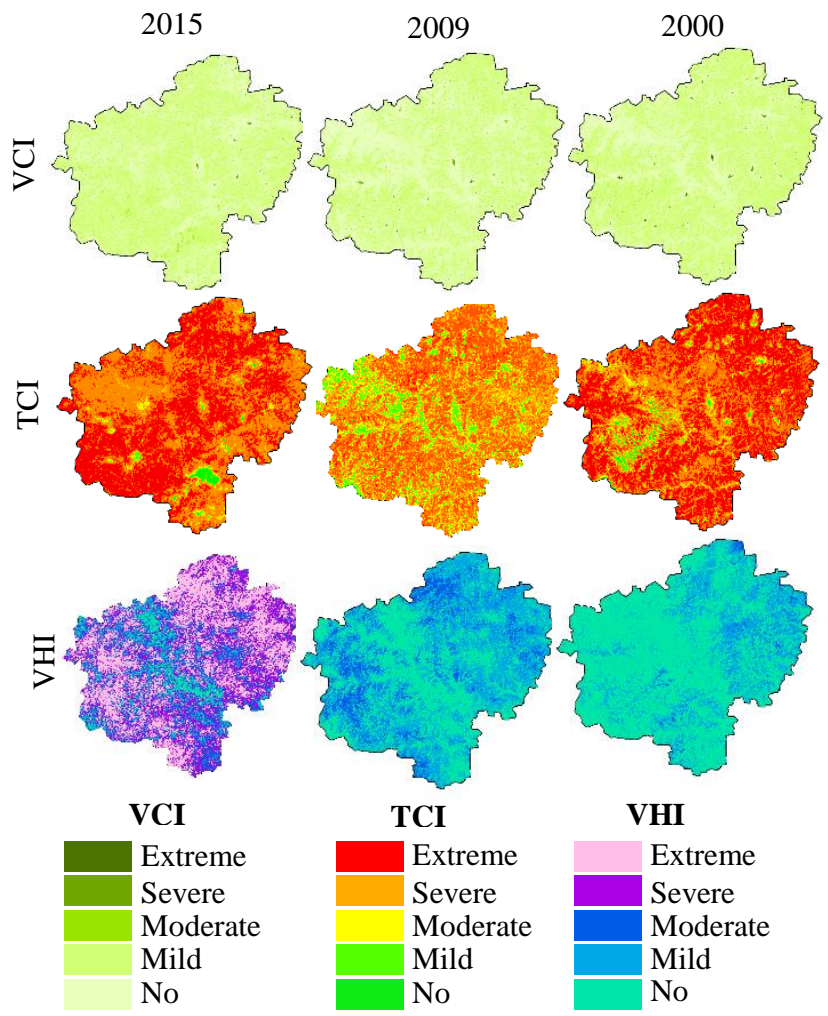

Figure 3: Spatial variation of drought due to soil moisture, thermal stresses and Vegetation health for April (Legends as per Table 1)

The spatial variation of drought affecting the vegetation cover, thermal stress and vegetation health is illustrated in figure 3 and figure 5. In figure 3, the temporal changes in VCI show the improved condition in 2009 than in 2000 but worsens again in 2015. Similarly, TCI shows severe to Moderate drought for 2009 meaning the vegetation conditions were better in 2009 as compared to 2000. The TCI for 2015 also shows high thermal stress in the region. Therefore, the total vegetation health for the region during all three years show severe to moderate drought conditions specifically after 2015 drought. In figure 5, the drought conditions are extreme for the year 2000 and 2009 for
VCI, whereas the TCI values show no drought condition in major part of the district. It means VCI is more sensitive in the wet seasons whereas the TCI works effectively only when the temperature is high. VCI is calculated using NDVI which shows the soil moisture condition. However, NDVI usually begins to saturate when vegetation cover is above 50\% and is insensitive to the greenness when vegetation cover is low leading to under or overestimation of vegetation cover giving false information for a region. Both the indices are dynamic in nature. TCI at lower values corresponds to vegetation stress due to high temperature whereas, VCI shows healthy and unstressed vegetation for higher values (Bhuiyan, 2008). Therefore, VHI is calculated to analyze the drought conditions more comprehensively for wet seasons and during high temperature leading to more precise results.

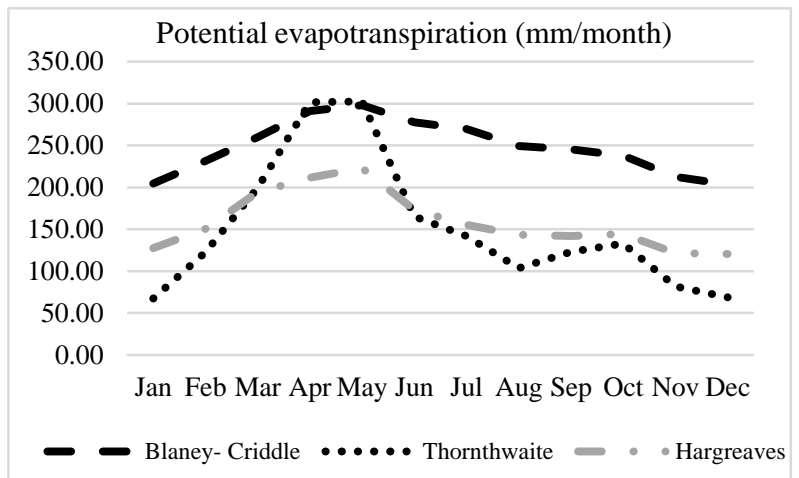

Figure 4: PET (mm/month) of Latur using three equations

A time series values with potential evapotranspiration (PET) has been calculated to understand the crop water stress condition and correlate with results from three indices. PET is calculated using three equations of Blaney-Criddle, Thornthwaite and Hargreaves (figure 4). The crop water stress in the month of April shows highest value which determines the poor vegetation condition and highly prone to drought. The three equations may underestimate

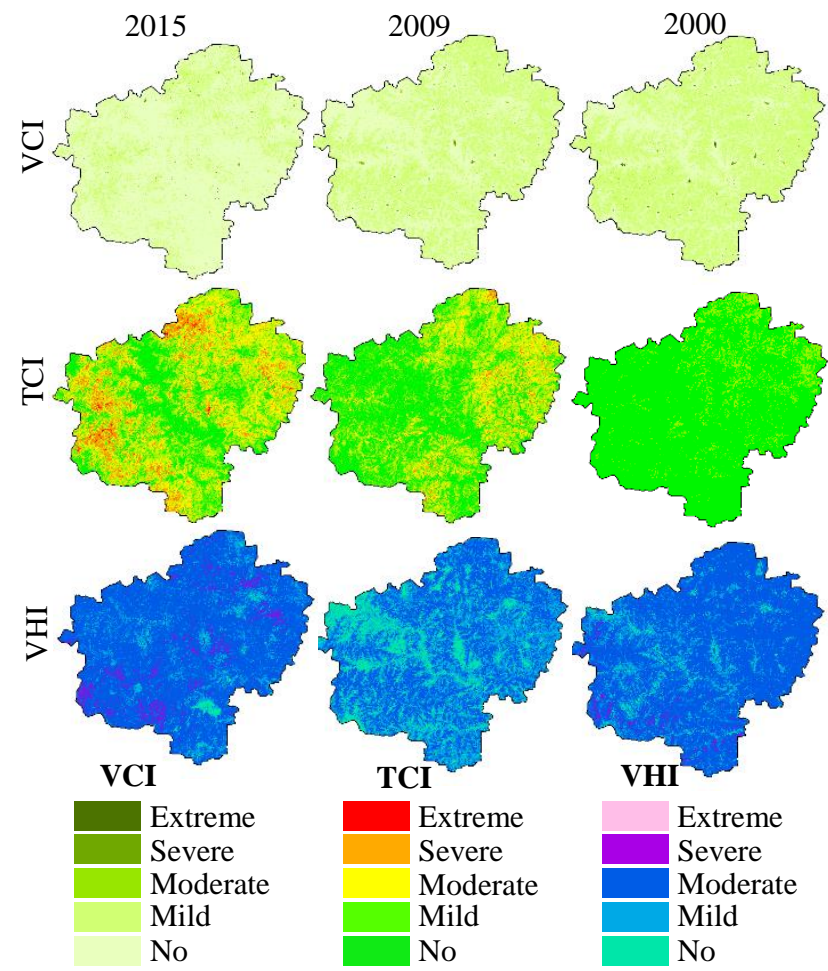

Figure 5: Spatial variation of drought due to soil moisture, thermal stresses and Vegetation health for December (Legends as per Table 1) 
the crop water stress for the months with low temperature specifically November to January as the input factor is monthly Temperature. As seen in figure 5, VCI and VHI shows severe drought conditions for the month of December, whereas PET and

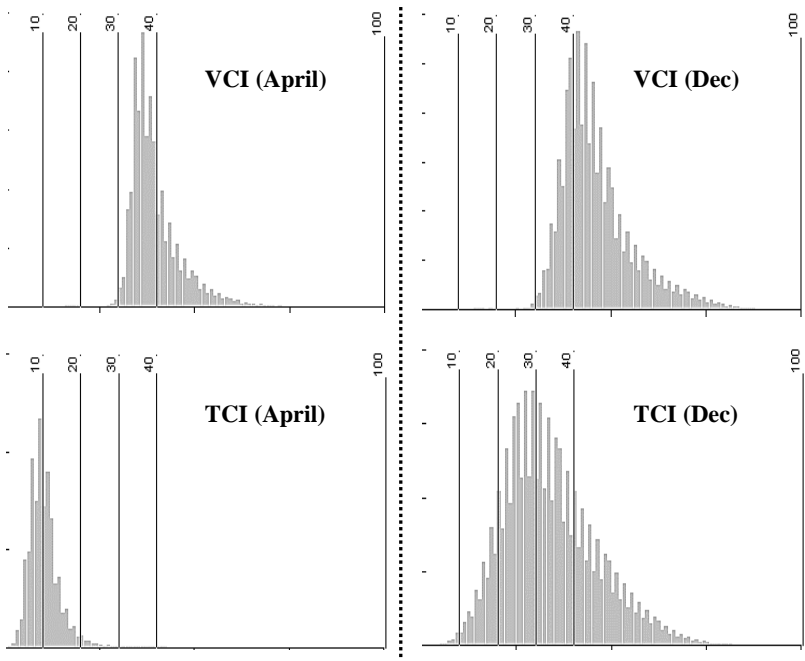

Figure 6: Illustrating the difference between VCI and TCI values of different time zone for 2015 (as per Table 1)

TCI shows low values interpreting no water stress in vegetation for Latur.

The histogram in figure 6 illustrates the difference in TCI and VCI values. One shows the extreme conditions, whereas the other detects moderate condition for the same time period. Hence, the combined approach using various parameters for estimating drought may lead to an improved analysis. Depending on one factor to assess drought condition for a region can be misleading.

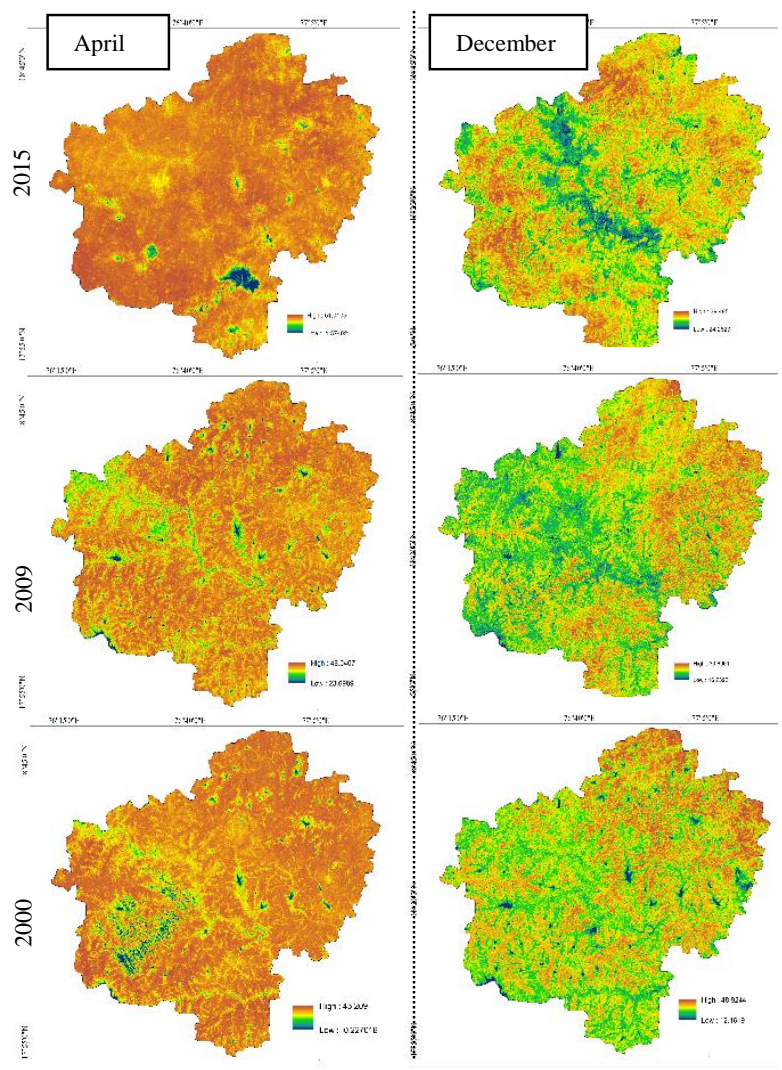

Figure 7: Spatial variation of LST for April and December
The Land Surface Temperature (LST) is determined from thermal bands which is the sixth band in Landsat 5 and 7 and for Landsat 8 it is the band 10 and 11 . Further, the spectral radiance (TOA) and BT are measured through these TIR bands to get LST of a specified geographical region. Figure 7 indicates that drought intensified in some parts of Latur from mild to severe and extreme conditions. The severity is primarily triggered by rise in temperature (LST) in the month of April from $45^{\circ} \mathrm{C}$ in 2000 to $51^{\circ} \mathrm{C}$ in 2015 . The spatial variation in figure 7 shows higher temperature values for April justifying the higher PET (figure 4) values for the same month. Also, in some parts of Latur during December shows high LST leading vegetative fields more susceptible to drought.

\section{CONCLUSION}

All the sectors of Latur areas are affected due to it prolonged drought conditions. Being mainly reliant on agriculture, Latur had a considerable loss in GDP during and after drought. Using three indices i.e., VCI, TCI and VHI, our study helps in analyzing the vegetation condition and its severity due to drought for a region.

These indices are designed to determine soil moisture condition (VCI), thermal stress using TCI and vegetation health from VHI derived from the combination of NDVI and LST. VCI calculates the impacts of drought on vegetation and its severity, by noting vegetation changes and comparing them with minimum and maximum values of NDVI detecting drought conditions as more sensitive during wet seasons. TCI defines the stress on vegetation caused by temperature and excessive wetness, which reflects different vegetation responses to temperature. The results through this index detect the drought only during the dry period or in the months where the temperature is high. Whereas, VHI combines both the indicators to give comprehensive results about drought conditions. It identifies, monitors and classifies the stress to vegetation due to drought. Our study shows that the comparative analysis of various indices represents a better interpretation and monitoring of drought for the areas which are largely affected due to vegetative drought. The drought conditions for Latur are worsening in the entire district where most of the areas have severe to moderate drought condition. The analysis shows that the region is facing severe agricultural drought conditions. The major crop grown in this region is Sugarcane which is a water intensive crop creating an imbalance in water supply and demand. Since the region is primarily affected by agricultural drought, there should be a change in cropping pattern, adoption of methods like drip irrigation, crop rotation and practicing rainwater harvesting may potentially reduce the impact of drought on the agricultural sector.

The assessment of agricultural drought can be used to review the effects of different crops leading to drought conditions. An integrated approach which looks at different parameters such as crop stress, soil moisture condition and groundwater levels will be useful for making informed policy decisions. Combining this approach with a mechanism for forecasting precipitation levels and meteorological drought indices on early warning for drought may lead to a systematic drought management solution.

\section{ACKNOWLEDGMENT}

The author would like to acknowledge the USGS for availing the Landsat data for conducting the research.

\section{REFERENCES}

Bhuiyan, C. (2004). Various drought indices for monitoring 
drought condition in Aravalli terrain of India. ISPRS International Journal of Geo-Information, 6. Retrieved from $\mathrm{http}: / /$ www.isprs.org/proceedings/xxxv/congress/comm7/papers /243.pdf

Bhuiyan, C. (2008). Desert vegetation during droughts: Response and sensitivity. The International Archives of the Photogrammetry, Remote Sensing and Spatial Information Sciences, XXXVII(Part B8), 907-912.

Felix N. Kogan. (2001). Operational space technology for global vegetation assessment. Bulletin of the American Meteorological Society, 82(9), 1949-1964. https://doi.org/10.1175/15200477(2001)082

Ghaleb, F., Mario, M., \& Sandra, A. (2015). Regional LandsatBased Drought Monitoring from 1982 to 2014. Climate, 3(3), 563-577. https://doi.org/10.3390/cli3030563

Kogan, F. (2002). World droughts in the new millennium from avhrr-based vegetation health indices. Eos, 83(48), 3-7. https://doi.org/10.1029/2002EO000382

Kogan, F., Spivak, L., Gitelson, A., Zakarin, E., \& Lebed, L. (2003). AVHRR-Based Spectral Vegetation Index for Quantitative Assessment of Vegetation State and Productivity: Calibration and Validation AVHRR-Based Spectral Vegetation Index for Quantitative Assessment of Vegetation State and Productivity: Calibration and Va. Photogrammetric Engineering \& Remote Sensing, 69(8), 899-906.

Sivakumar, M. V. K., Stone, R., Sentelhas, P. C., Svoboda, M., Omondi, P., Sarkar, J., \& Wardlow, B. (2011). Agricultural Drought Indices: Summary and Recommendations. In S. V. K. Mannava, R. P. Motha, D. A. Wilhite, \& D. A. Wood (Eds.), Agricultural Drought Indices Proceedings of a WMO Expert Meeting held in Murcia, Spain (p. 197). Murcia, Spain: World Meteorological Organization (WMO). AGM-11, WMO/TD No. 1572; WAOB-2011.

Svoboda, M., \& Fuchs, B. (2017). Handbook of Drought Indicators and Indices*. In Integrated Drought Management Tools and Guidelines Series (pp. 155-208). Geneva: INDP. https://doi.org/10.1201/9781315265551-12

Wilhite, D. A. (Ed.). (2005). Drought and water crisis : science, technology, and management issues. CRC Press and Taylor \& Francis Group. Retrieved from http://www.usda.gov/wps/portal/usda/usdahome?navid=DISAS TER_ASSISTANCE

Wilhite, D. A., \& Glantz, M. H. (1985). Understanding: the Drought Phenomenon: The Role of Definitions. Water International; Drought Mitigation Center Faculty Publications, 10(3), 111-120. https://doi.org/10.1080/02508068508686328org/10.1080/02508 068508686328

Wilhite, D. A., \& Glantz, M. H. (1987). Understanding: The drought phenomenon: The role of definitions. Drought Mitigation Center Faculty Publications, 10(3), 111-120. https://doi.org/10.1080/02508068508686328 